Prepared for the U.S. Department of Energy

under Contract DE-AC05-76RL01830

\title{
Majorana Thermosyphon Prototype Experimental Setup
}

\author{
DJ Reid \\ AD Guzman \\ JT Munley
}

August 2011

\section{Pacific Northwest}

NATIONAL LABORATORY

Proudly Operated by Battelle Since 1965 



\section{DISCLAIMER}

This report was prepared as an account of work sponsored by an agency of the United States Government. Neither the United States Government nor any agency thereof, nor Battelle Memorial Institute, nor any of their employees, makes any warranty, express or implied, or assumes any legal liability or responsibility for the accuracy, completeness, or usefulness of any information, apparatus, product, or process diselosed, or represents that its use would not infringe privately owned rights. Reference herein to any specific commercial product, process, or service by trade name, trademark, manufacturer, or otherwise does not necessarily constitute or imply its endorsement, recommendation, or favoring by the United States Government or any agency thereof, or Battelle Memorial Institute. The views and opinions of authors expressed herein do not necessarily state or reflect those of the United States Government or any agency thereof.

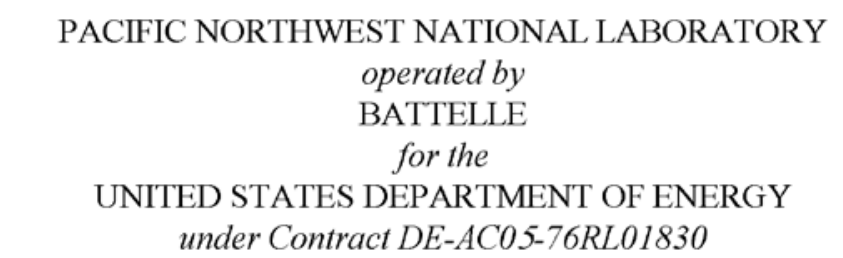

Printed in the United States of America

Available to DOE and DOE contractors from the Office of Scientific and Technical Information,

P.O. Box 62, Oak Ridge, TN 37831-0062; ph: (865) 576-8401 fax: (865) 576-5728

email: reports@adonis.osti.gov

\footnotetext{
Available to the public from the National Technical Information Service, U.S. Department of Commerce, 5285 Port Royal Rd., Springfield, VA 22161 ph: (800) 553-6847 fax: (703) 605-6900 email: orders@ntis.fedworld.gov online ordering: http://www.ntis.gov/ordering.htm
} 



\title{
Majorana Thermosyphon Prototype Experimental Setup
}

\author{
DJ Reid \\ AD Guzman \\ JT Munley
}

August 2011

Prepared for

the U.S. Department of Energy

under Contract DE-AC05-76RL01830

Pacific Northwest National Laboratory

Richland, Washington 99352 



\section{Abstract}

This report presents the experimental setup of Pacific Northwest National Laboratory's (PNNL’s) MAJORANA DEMONSTRATOR thermosyphon prototype cooling system. A nitrogen thermosyphon prototype of such a system has been built and tested at PNNL. This document presents the experimental setup of the prototype that successfully demonstrated the heat transfer performance of the system. 



\section{Acronyms and Abbreviations}

PNNL

TC

psig
Pacific Northwest National Laboratory

thermocouple

pounds per square inch gauge 



\section{Contents}

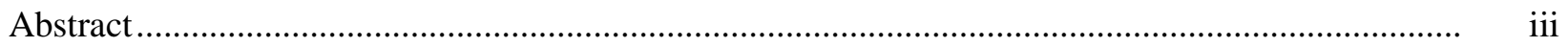

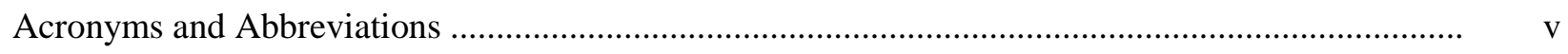

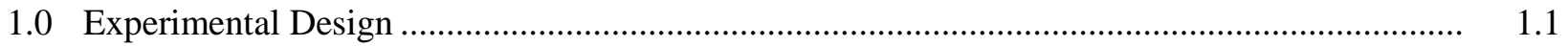

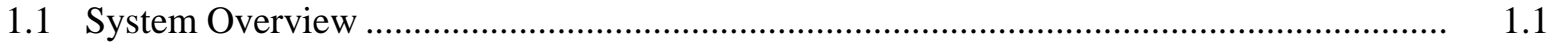

1.2 Cryogenic Cooling and Heat Transport..................................................................... 1.2

1.3 Vacuum Housing/Pumping and Thermal Insulation .......................................................... 1.6

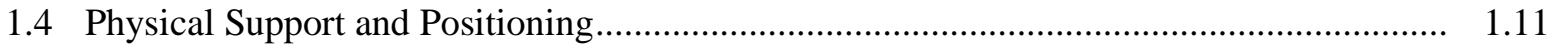

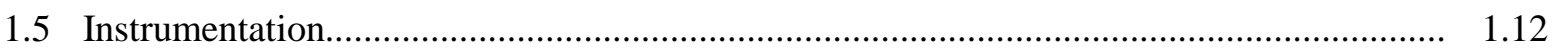

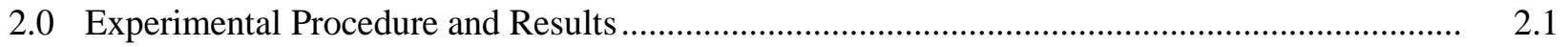

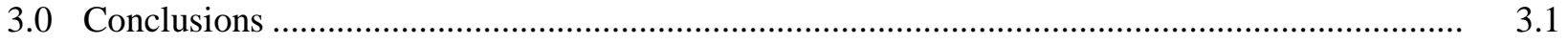

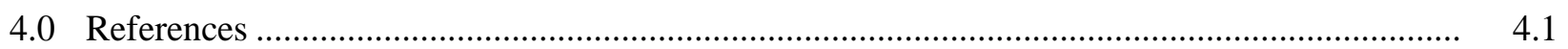




\section{Figures}

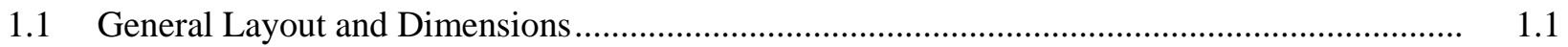

1.2 Model of the Thermosyphon Setup at PNNL ..................................................................... 1.2

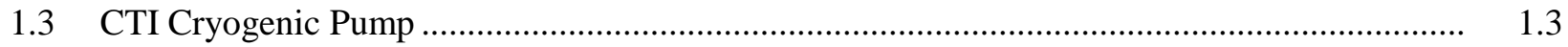

1.4 Rear Panel of Cryogenic Pump Compressor......................................................................... 1.4

1.5 PEEK Insulating Support ......................................................................................... 1.4

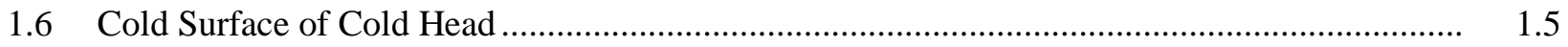

1.7 Interface Flange between Cold Finger and CTI Cryogenic Unit ............................................. 1.5

1.8 Complete Apparatus in Extruded-Aluminum Support Frame..................................................... 1.6

1.9 Explosively Welded Copper-to-Stainless Steel Transition ....................................................... 1.7

1.10 Cold-Head Interface Area with Nitrogen Supply Line ............................................................ 1.7

1.11 Nitrogen Supply to Bulkhead CF Flange ........................................................................... 1.8

1.12 Thermosyphon Connection with Large Bellows Retracted for Final Assembly....................... 1.8

1.13 Mylar Reflective Film Around Thermosyphon Tube .............................................................. 1.9

1.14 Mylar Film around Nitrogen Supply Line .................................................................... 1.9

1.15 Mylar Film at Final Vacuum Closure Point .......................................................................... 1.10

1.16 Apparatus Connected to Leybold Quadrupole Mass Spectrometer ......................................... 1.10

1.17 Apparatus Central Chamber Connected to Vacuum Pump ..................................................... 1.11

1.18 Magnetic Level Used to Monitor System Tilt........................................................................ 1.11

1.19 Thermocouple Placement Along the Copper Tube .................................................................. 1.12

1.20 Insulating Support and Hose Clamp Mounting Thermocouple to Copper Tube ....................... 1.13

1.21 Band Heater Clamped at the End of the Copper Tube............................................................. 1.13

1.22 Heater Power Feedthrough................................................................................................ 1.14

1.23 Thermocouple Feedthrough .................................................................................... 1.14 


\subsection{Experimental Design}

Prior to building the thermosyphon setup, a three-dimensional SolidWorks ${ }^{1}$ model was built (Figures 1.1 and 1.2)

\subsection{System Overview}

Figure 1.1 provides approximate dimensions in inches.

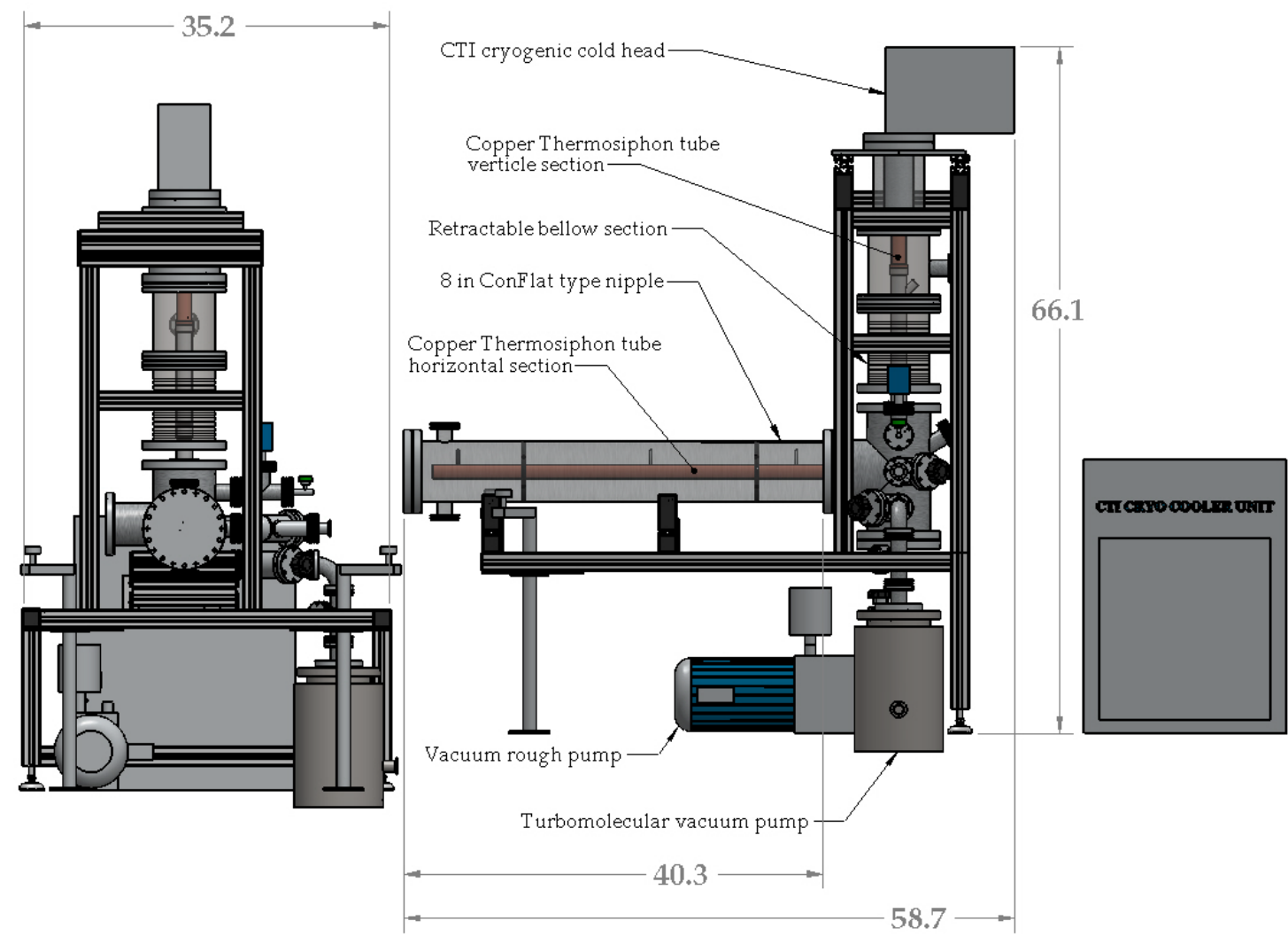

Figure 1.1. General Layout and Dimensions

This apparatus was assembled from a combination of commercial off-the-shelf components and custom fabricated hardware comprising four subsystems:

1. Cryogenic cooling and heat transport

2. Vacuum housing/pumping and thermal insulation

3. Physical support and positioning

4. Instrumentation

\footnotetext{
${ }^{1}$ Dassault Systèmes SolidWorks Corp.
} 


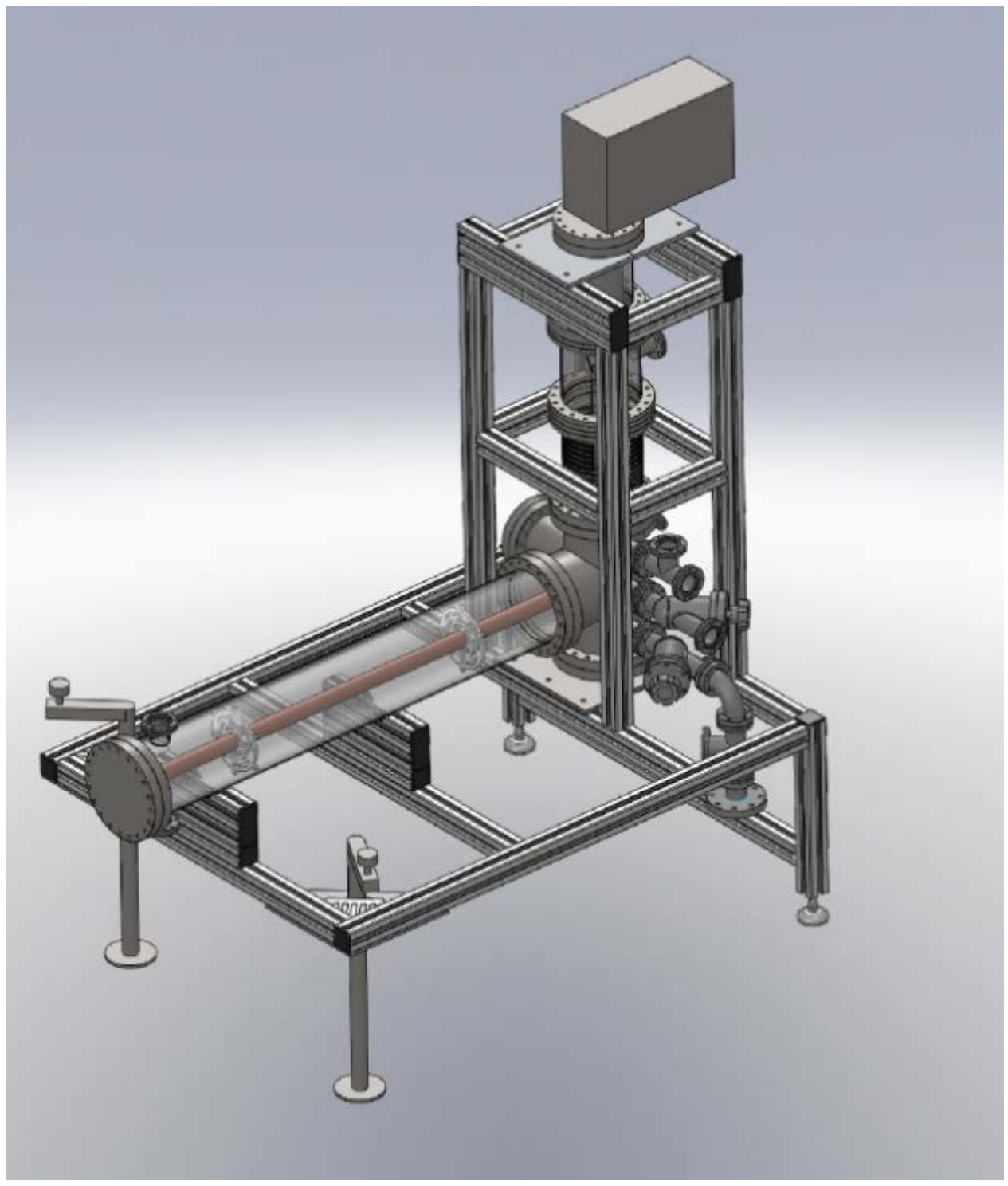

Figure 1.2. Illustration Showing the Horizontal Condenser Tube in the PNNL Thermosyphon

\subsection{Cryogenic Cooling and Heat Transport}

The thermosyphon has three main components: a condenser, an evaporator, and a vertical column that connects these two modules. The condenser for this experimental system is a mechanically cooled vertical copper rod acting as a cold finger. The mechanical cooler is a CTI-Cryogenics ${ }^{\circledR}$ helium refrigerator system ${ }^{2}$ composed of a Model 8510 compressor and a cold head. The cold head is capable of extracting $\sim 60 \mathrm{~W}$ at $80 \mathrm{~K}$. The cooler is thermally coupled to the cold finger through a layer of indium. The evaporator is a horizontal copper pipe with a length matching that of the pipe going through the MAJORANA DEMONSTRATOR shield (see Figure 1.2). The experimental setup allows for the evaporator tube to be tilted in order to explore performance limits and the effect of a slight slope toward or away

\footnotetext{
${ }^{2}$ Helix Technology Corporation Model 1050 Cryodyne Refrigeration system. http:helixtechnology.com
} 
from the evaporator tip where the primary heat load is applied. Figure 1.2 shows the computer-aided design model with the outer vacuum jacket shown transparent for clarity.

The heat transfer in the thermosyphon is carried out through evaporation and condensation of the twophase nitrogen in the system. The thermosyphon tube volume is connected to an external pressurized nitrogen tank (ballast tank) with a volume much larger than that of the tube so that the system can be initially charged with a moderate nitrogen gas pressure at room temperature and sealed prior to cool down. The amount of nitrogen remains constant during operation. The total volume of nitrogen is equal to the internal volume of the evaporator tube plus the volume of the vertical column connected to the condenser plus the nitrogen gas ballast tank (approximately 40 liters). As the system is cooled and nitrogen gas condenses to liquid phase, the pressure in the system falls to near atmospheric pressure. Using a large volume ballast tank reduces the pressure requirements of the thermosyphon tube when all of the nitrogen is in the gaseous state, reducing the engineering and safety challenges of a highly pressurized system. The system operating pressure of 0 to 60 psig was monitored using a pressure gauge located on the line connecting the ballast tank to the thermosyphon body.

Figure 1.3 is the cryogenic pump used to cool the cold head of this apparatus.

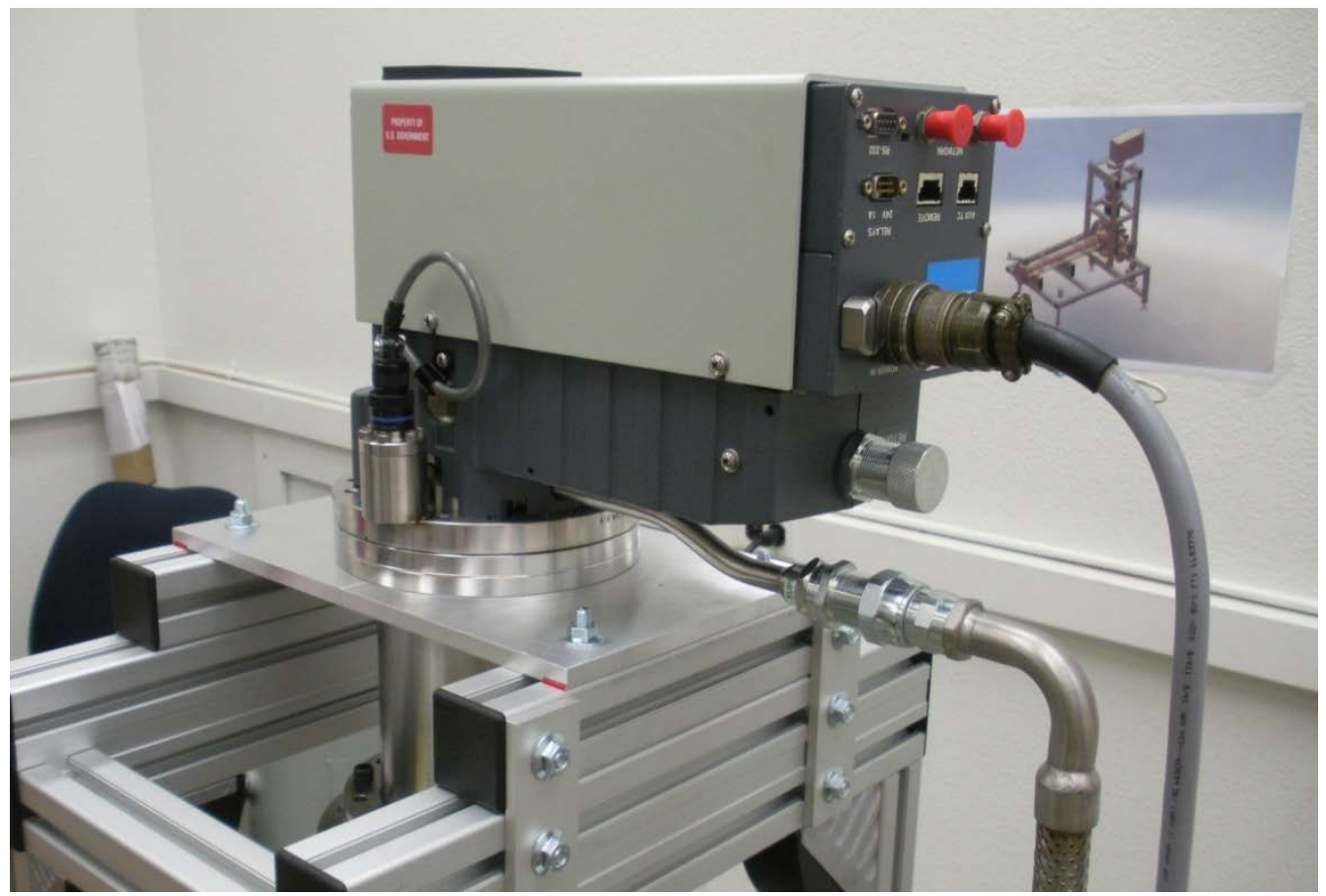

Figure 1.3. CTI Cryogenic Pump

Figure 1.4 shows the rear panel of the cryogenic pump compressor. The braided lines transport the compressed helium to the pump unit shown in Figure 1.3. 


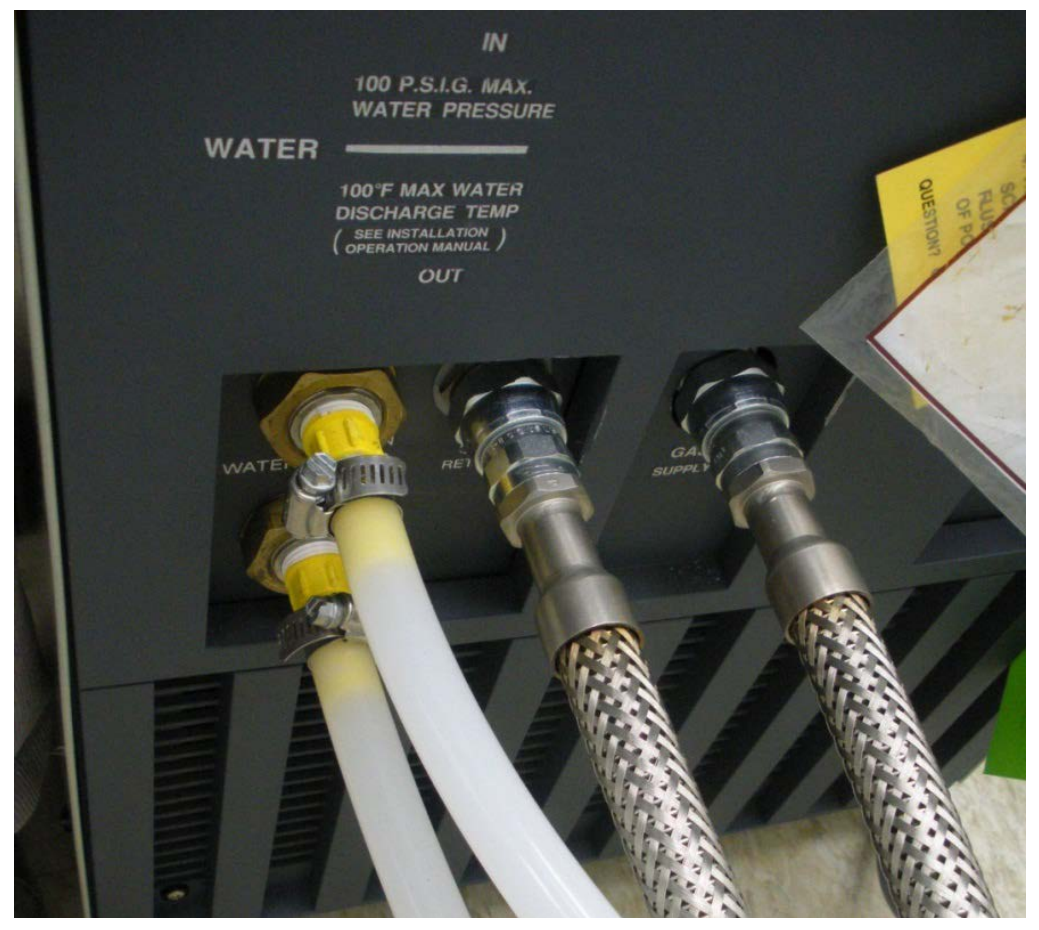

Figure 1.4. Rear Panel of Cryogenic Pump Compressor

Figure 1.5 shows the thermal insulating $\mathrm{PEEK}^{3}$ piece used to support the copper tube inside the vacuum jacket.

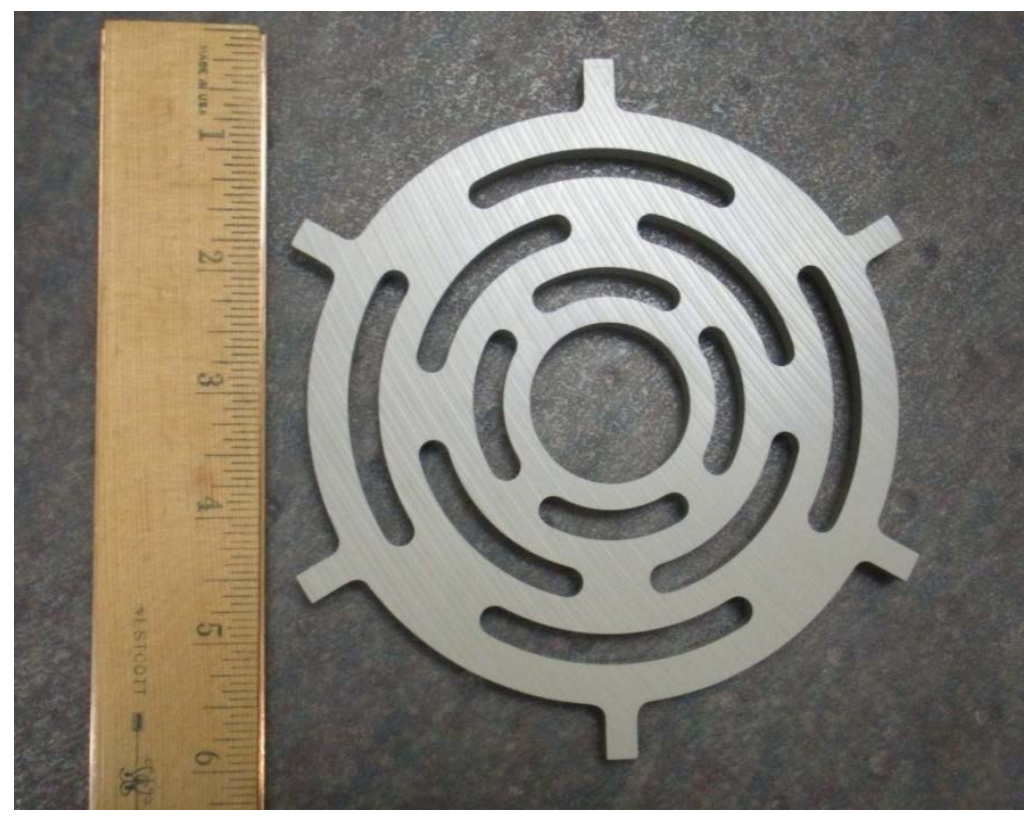

Figure 1.5. PEEK Insulating Support

\footnotetext{
${ }^{3}$ PEEK = polyether ether ketone
} 
Figure 1.6 shows the cold surface of the cold head. The silver-colored material is a soft indium layer for thermal contact with the cold finger.

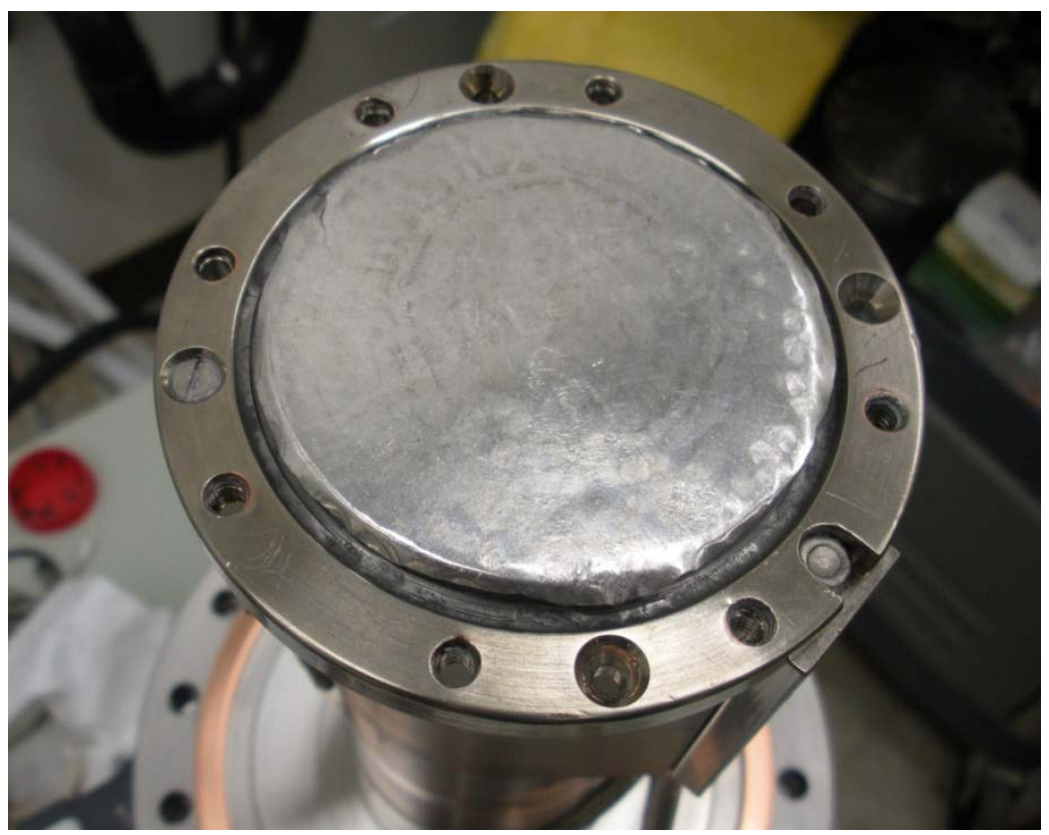

Figure 1.6. Cold Surface of Cold Head

Figure 1.7 shows the copper interface flange that connects the thermosyphon tube to the cold head of the CTI cryogenic unit.

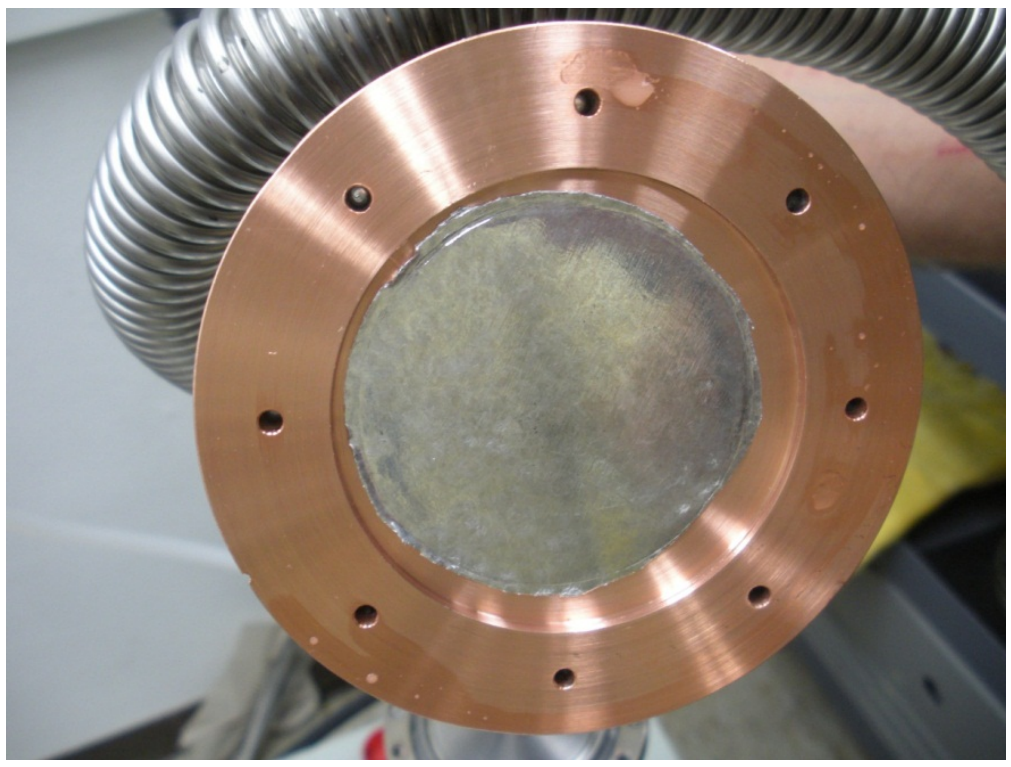

Figure 1.7. Interface Flange between Cold Finger and CTI Cryogenic Unit 


\subsection{Vacuum Housing/Pumping and Thermal Insulation}

All vacuum components were of the copper gasket/knife edge style typically associated with the Conflat brand. Note that some of the vacuum components were fitted with Viton ${ }^{\circledR 4}$ gaskets rather than copper. Figure 1.8 shows the test setup in the laboratory.

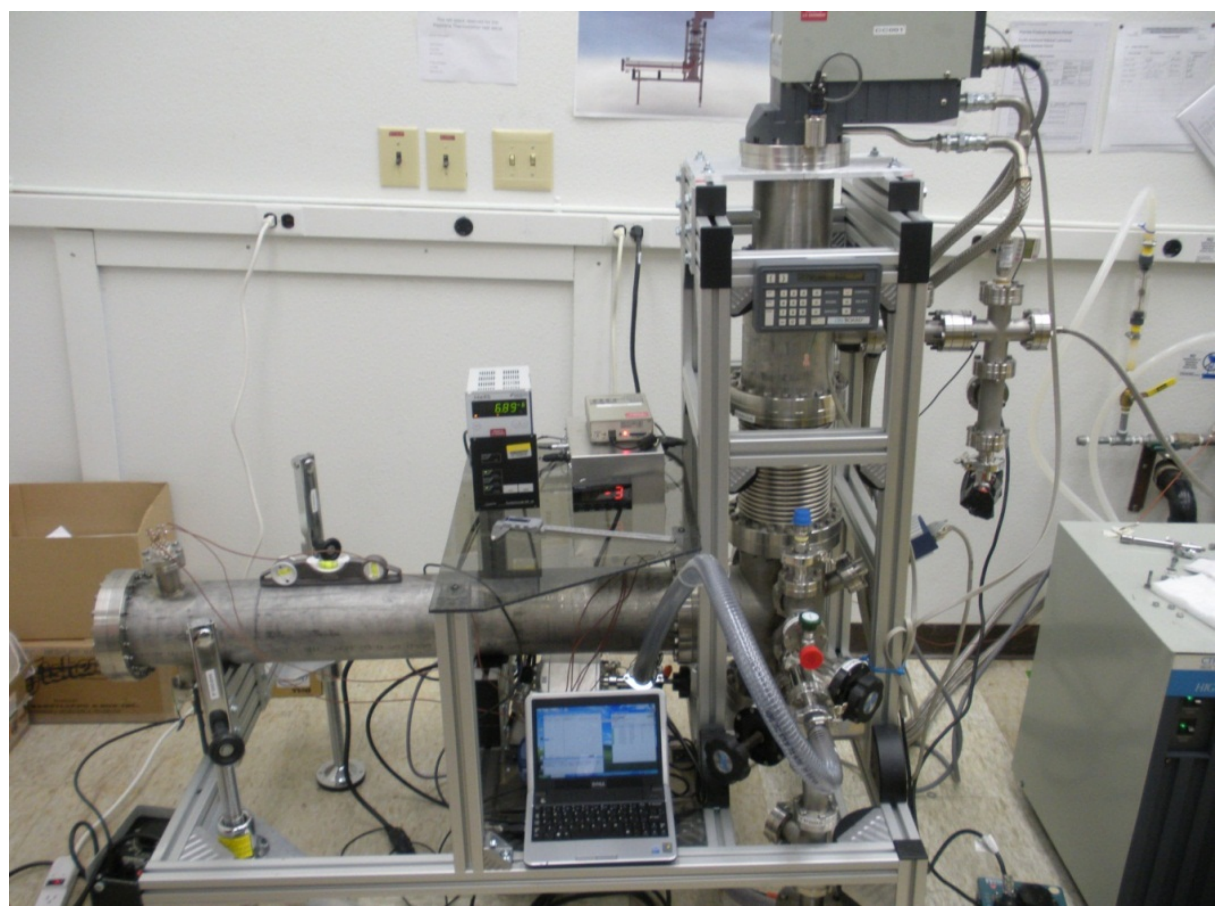

Figure 1.8. Complete Apparatus in Extruded-Aluminum Support Frame

Figure 1.9 shows the copper-to-stainless-steel transition used to couple the thermosyphon tube to the CTI Cryogenic pump.

\footnotetext{
${ }^{4}$ Viton is a registered trademark of DuPont Performance Elastomers L.L.C.
} 


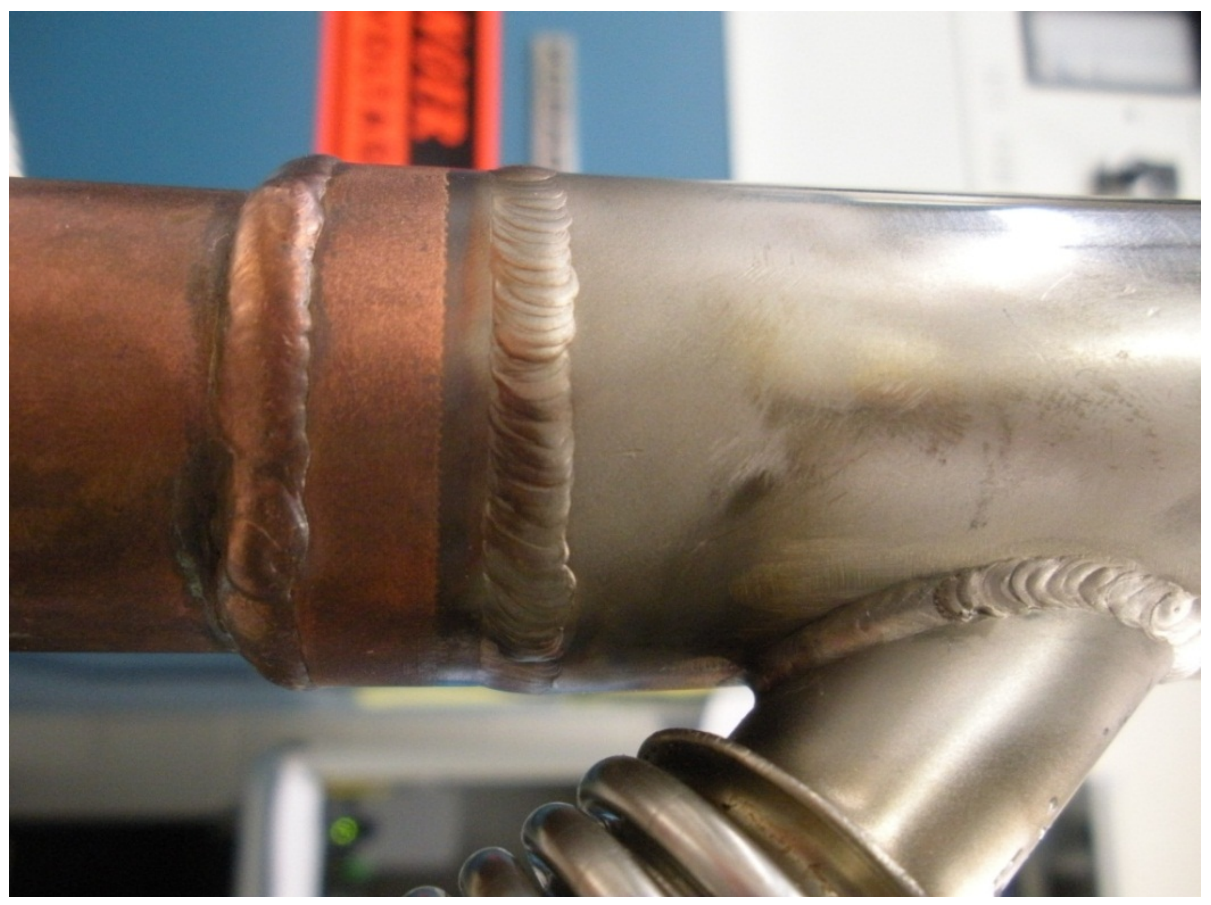

Figure 1.9. Explosively Welded Copper-to-Stainless-Steel Transition

Figure 1.10 shows the underside of the thermosyphon tube bolted to the cold head. Note the coiled stainless steel bellows which supplied nitrogen from the ballast tank to the thermosyphon.

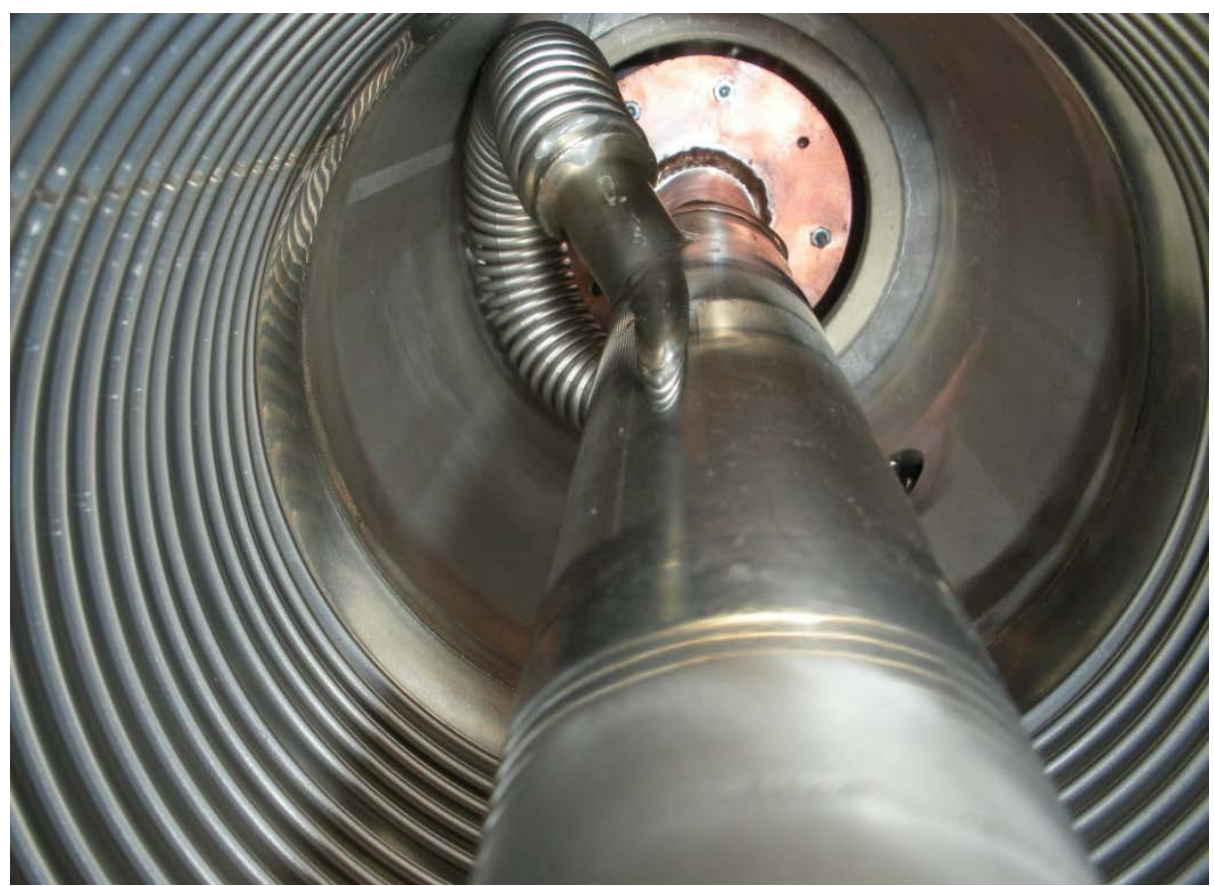

Figure 1.10. Cold-Head Interface Area with Nitrogen Supply Line 
Figure 1.11 shows the nitrogen supply exiting the vacuum chamber via a bulkhead CF flange with a $1 / 2$-in. $\operatorname{VCR}^{\circledR}$ fitting welded in its center.

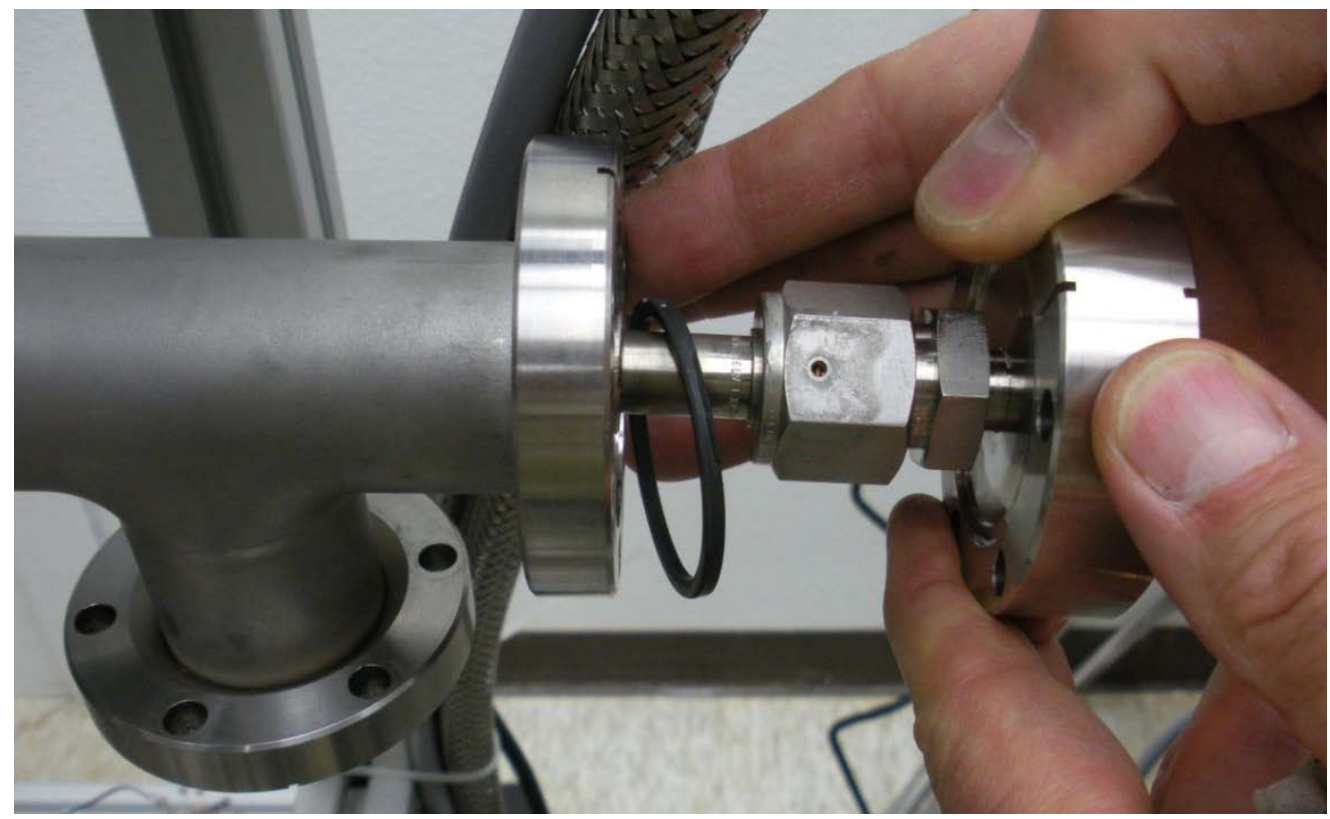

Figure 1.11. Nitrogen Supply to Bulkhead CF Flange

Figure 1.12 shows the apparatus with the large diameter stainless steel bellows retracted to allow access to the final thermosyphon connection. It was necessary to assemble the apparatus in two halves and then connect these two halves via the access provided by retracting the bellows; see Figure 1.1 for clarity.

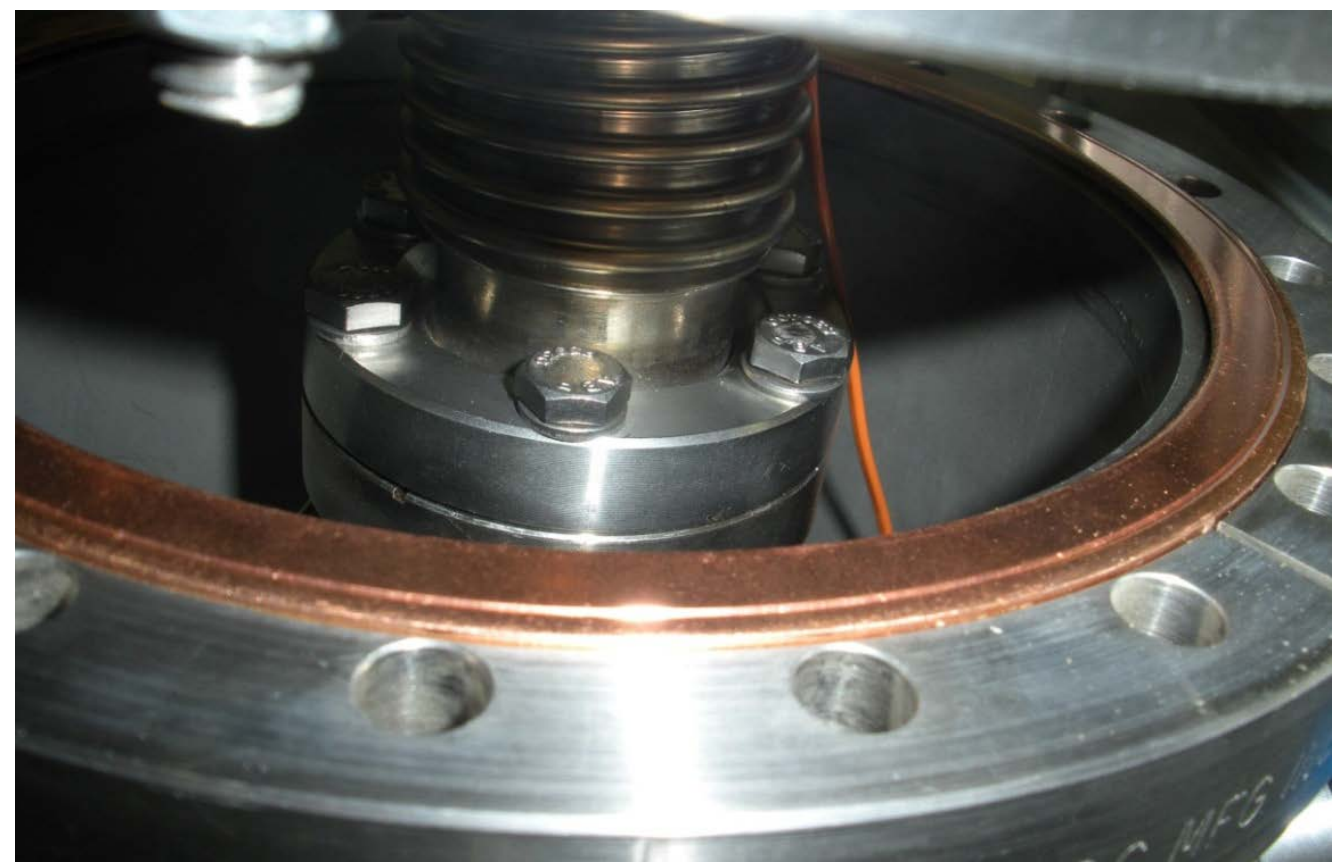

Figure 1.12. Thermosyphon Connection with Large Bellows Retracted for Final Assembly 
Multiple layers of Mylar ${ }^{\circledR 5}$ film were wrapped around the thermosyphon tube to reflect black body radiation away from the vacuum housing, which was at room temperature; see Figure 1.13.

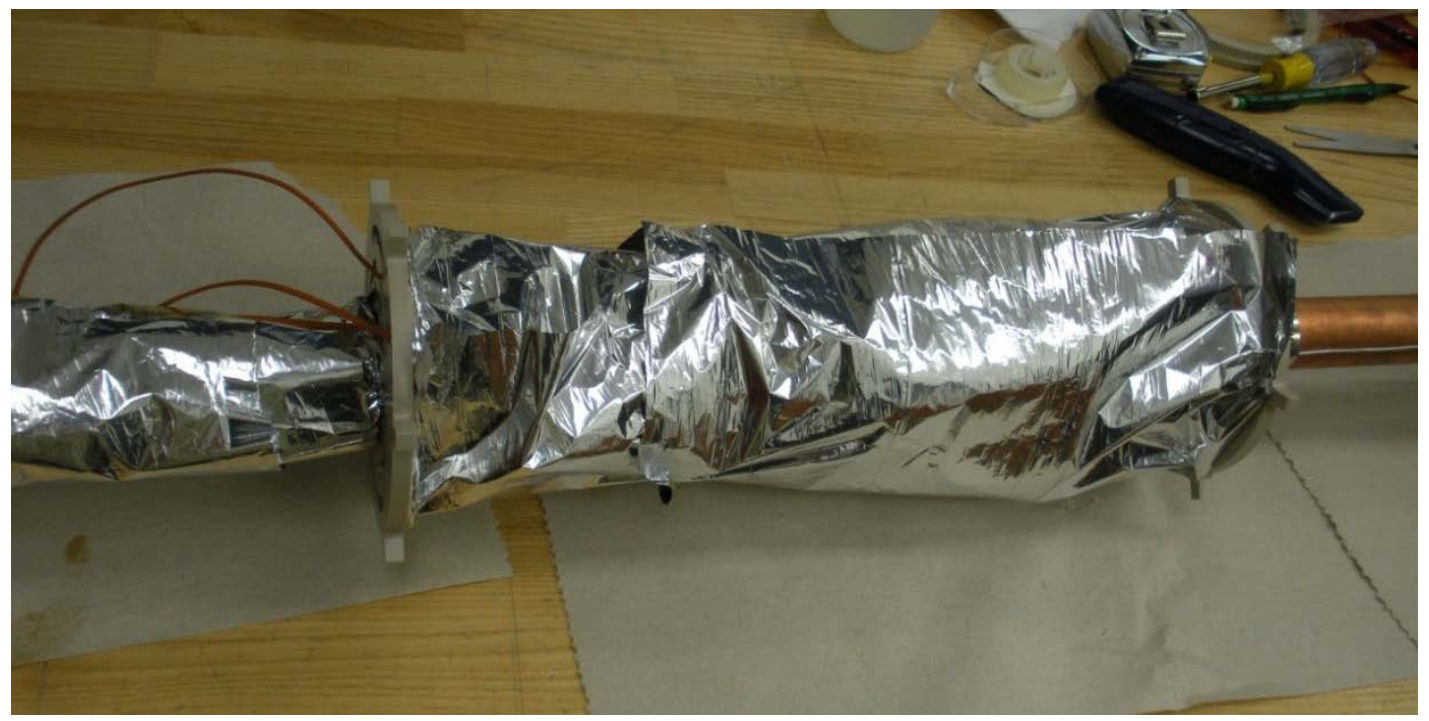

Figure 1.13. Mylar Reflective Film around Thermosyphon Tube

Figure 1.14 shows the Mylar installed around the nitrogen supply line bellows.

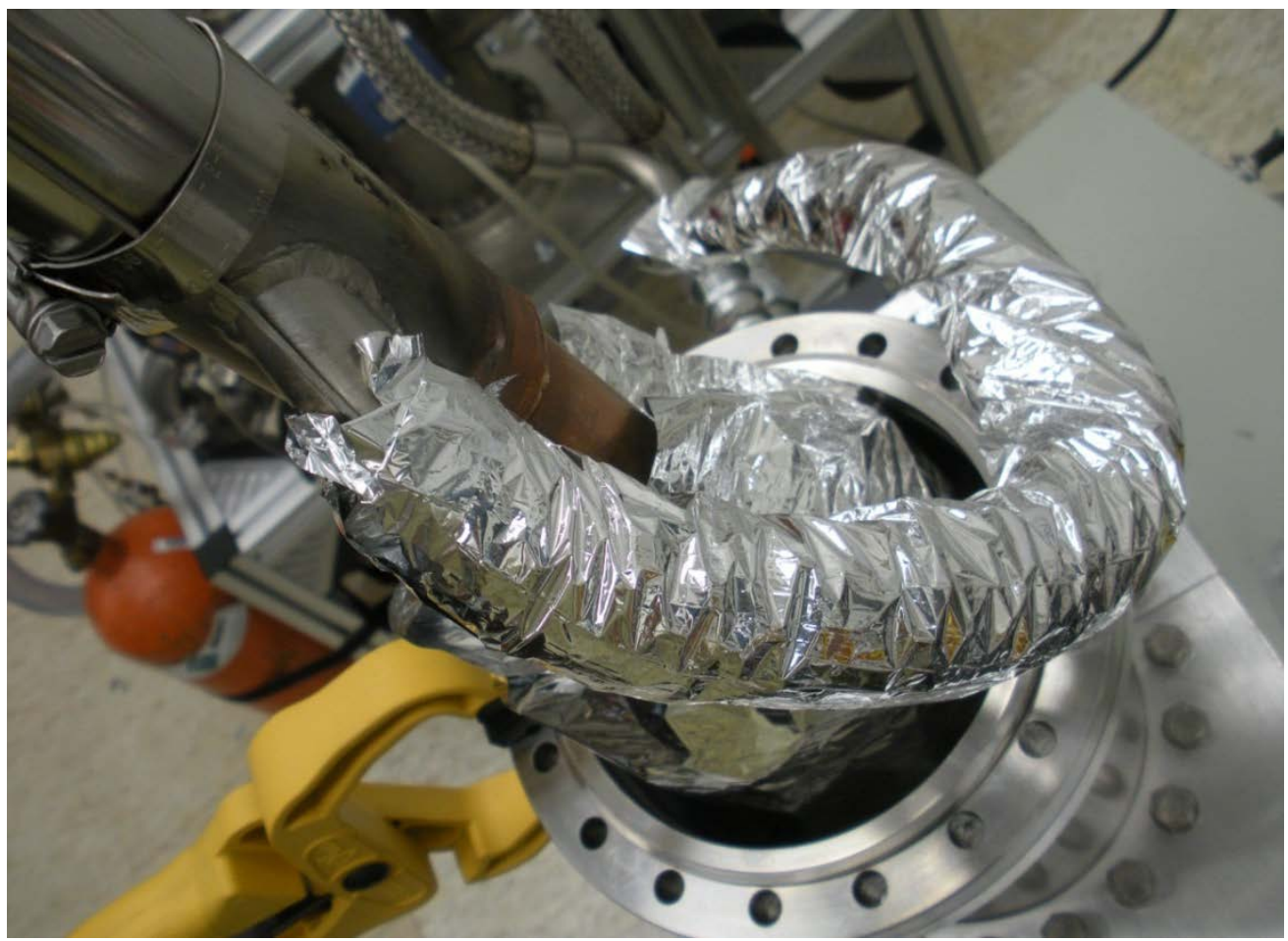

Figure 1.14. Mylar Film around Nitrogen Supply Line

\footnotetext{
${ }^{5}$ Mylar is a registered trademark of DuPont Tejjin Films.
} 
Figure 1.15 shows the installation of Mylar prior to final closure.

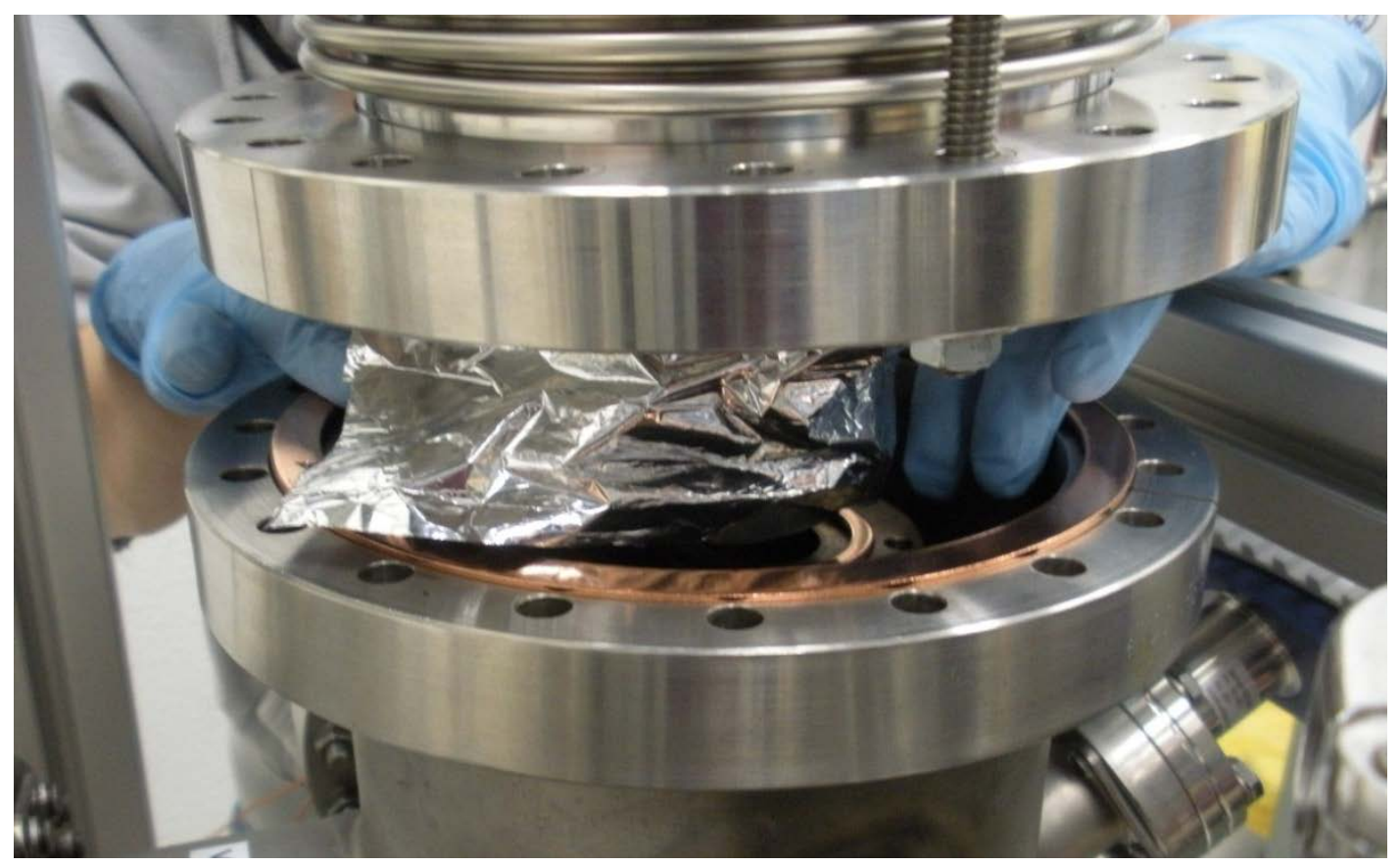

Figure 1.15. Mylar Film at Final Vacuum Closure Point

Figure 1.16 shows the complete apparatus connected to a Leybold quadrupole mass spectrometer. The mass spectrometer was used in helium leak-test mode to test the vacuum integrity after final assembly.

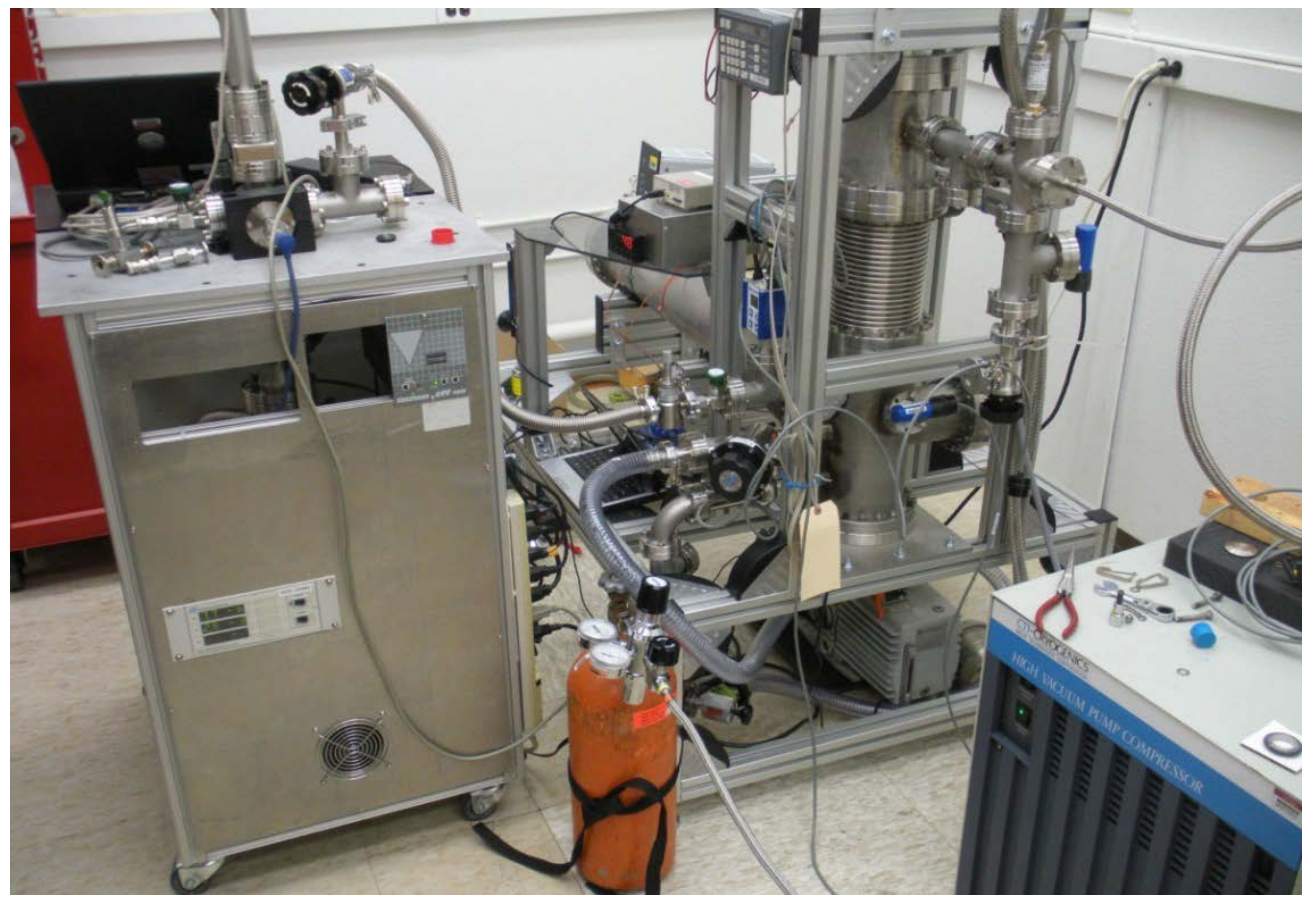

Figure 1.16. Apparatus Connected to Leybold Quadrupole Mass Spectrometer 


\subsection{Physical Support and Positioning}

The system was assembled from the middle outward, beginning by connecting the central vacuum chamber to the vacuum pump and conducting leak tests to verify vacuum tightness (see Figure 1.17). After this chamber was tested satisfactorily, each section was added and vacuum tested until the vacuum jacket was complete.

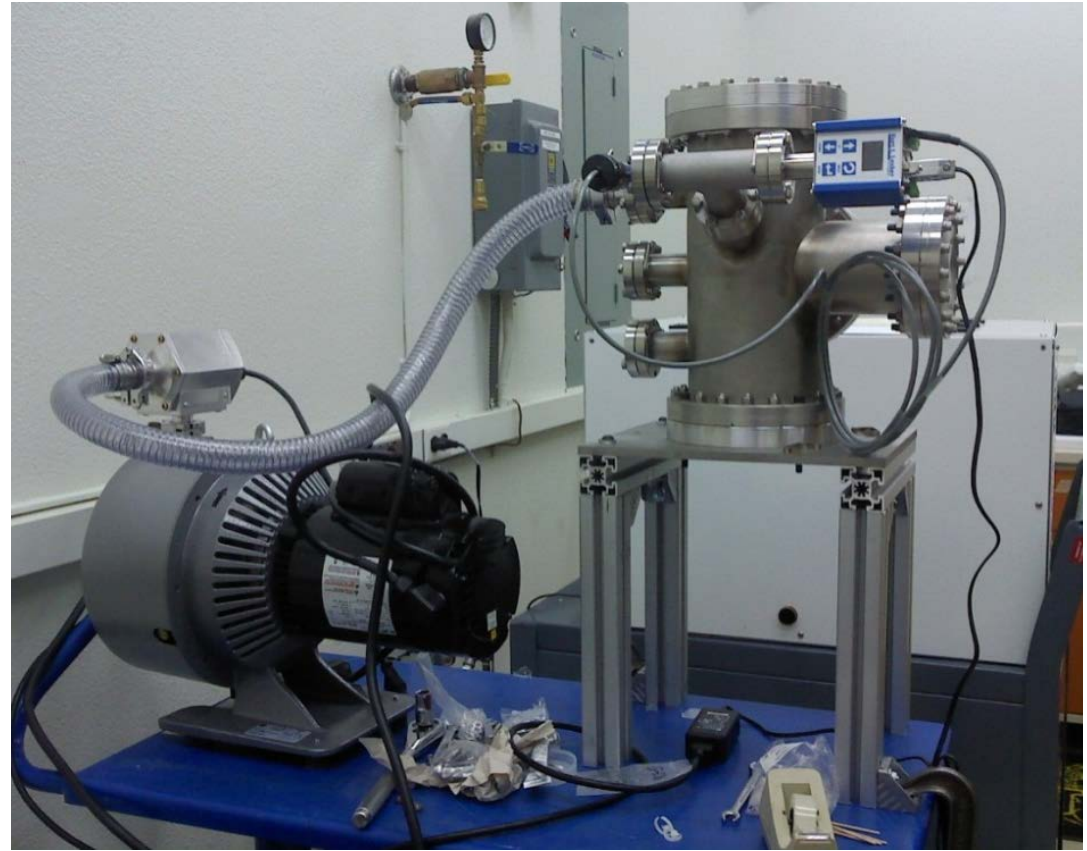

Figure 1.17. Apparatus Central Chamber Connected to Vacuum Pump

Figure 1.18 shows the level used to monitor the tilt of the experiment.

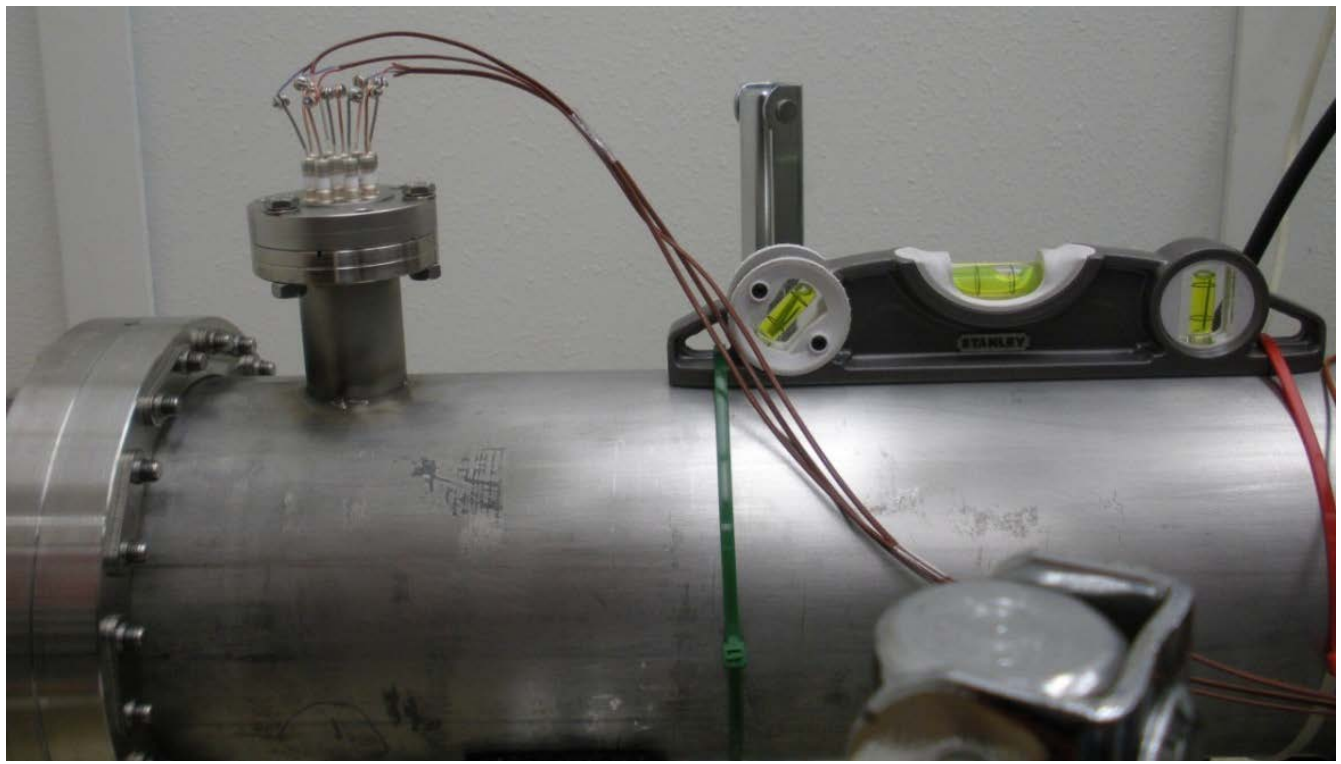

Figure 1.18. Magnetic Level Used to Monitor System Tilt 


\subsection{Instrumentation}

The measure of success for the thermosyphon was its ability to transport heat from the heater at the far end of the copper tube to the cold head at the other end. Thermocouples mounted along the condenser tube were used to measure the temperature distribution as the liquid nitrogen made its way to the heated end and ultimately reached thermal equilibrium with the heat load. Thermocouple placement is shown in Figure 1.19. Thermocouple TC1 was located 4 inches away from the tip of the tube, TC2 was located 21 inches away from the tip, TC4 was located 36 inches away from the tip, and TC5 was located at the elbow leading to the condenser. Additional thermocouples were located within one of the PEEK supports for the evaporator tube (TC3) and at the condenser (TC6).

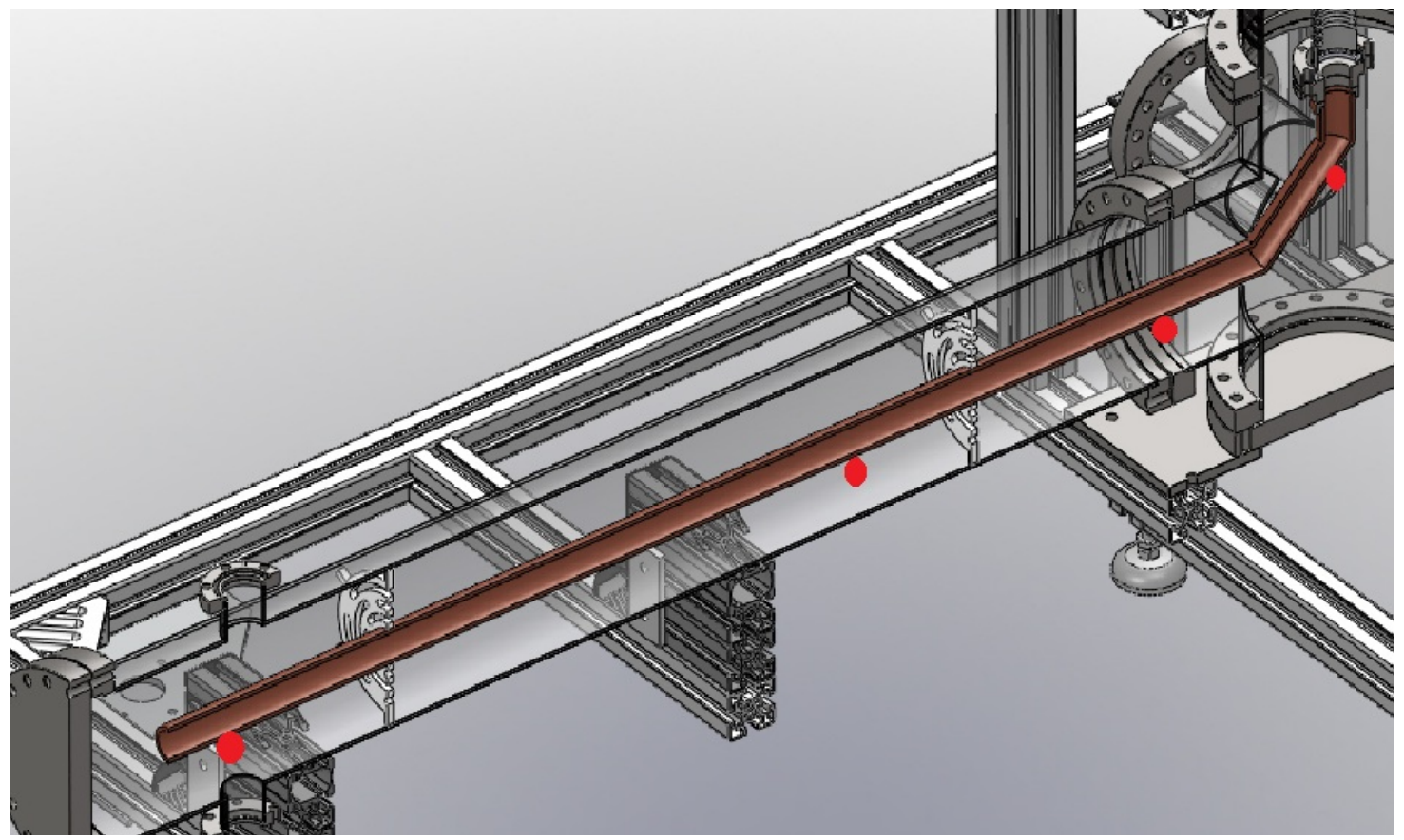

Figure 1.19. Placement of Thermocouples TC1 through TC4 from Left to Right along the Copper Evaporator Tube

Figure 1.20 shows one of the PEEK thermal insulators used to thermally isolate the copper tube from the outer vacuum housing. Also shown in Figure 1.20 is a stainless steel hose clamp holding one of the thermocouples in intimate contact with the copper tube. 


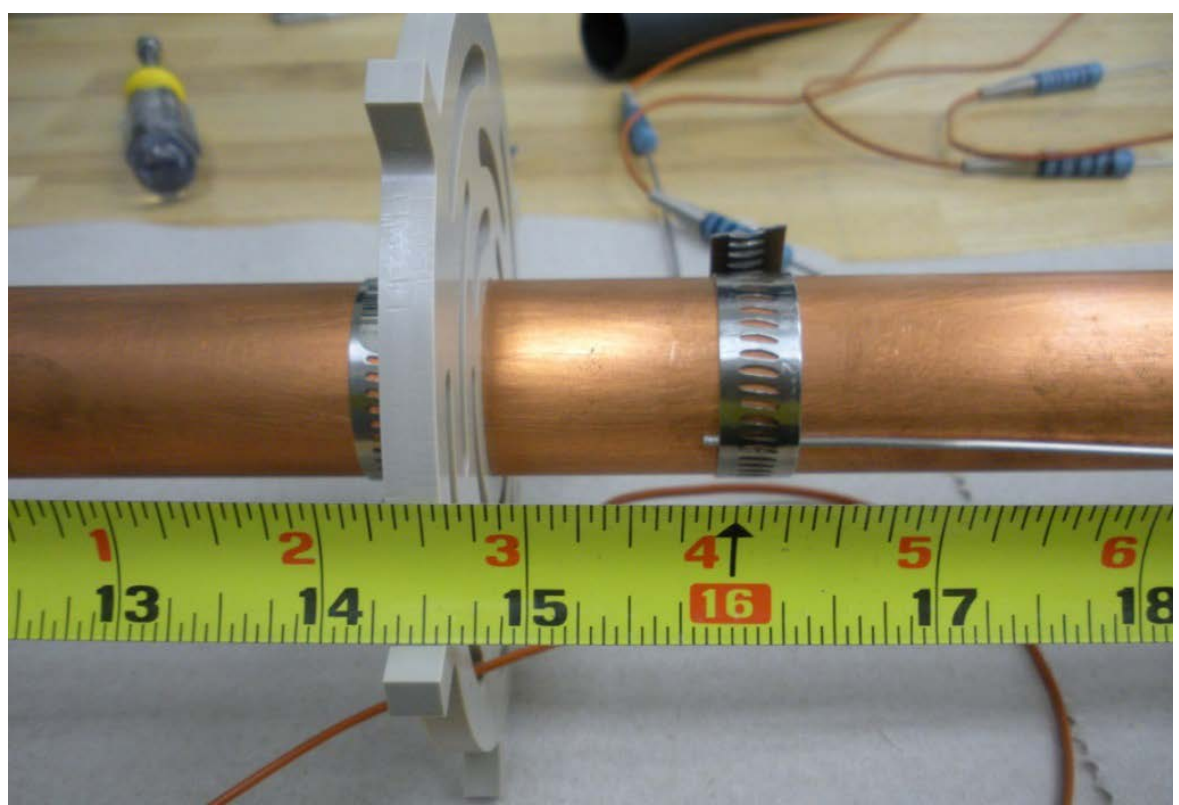

Figure 1.20. Insulating Support and Hose Clamp Mounting Thermocouple to Copper Tube

An adjustable electric heater (Figure 1.21) was placed at the tip of the tube to emulate the heat load created by the detector module. The adjustable heater at the tip of the evaporator tube was used to apply different heat loads within the range of interest, from $0 \mathrm{~W}$ to $25 \mathrm{~W}$. The operating point of the two-phase nitrogen system was regulated by adjusting the cold-head temperature using a second heater embedded in the cold head.

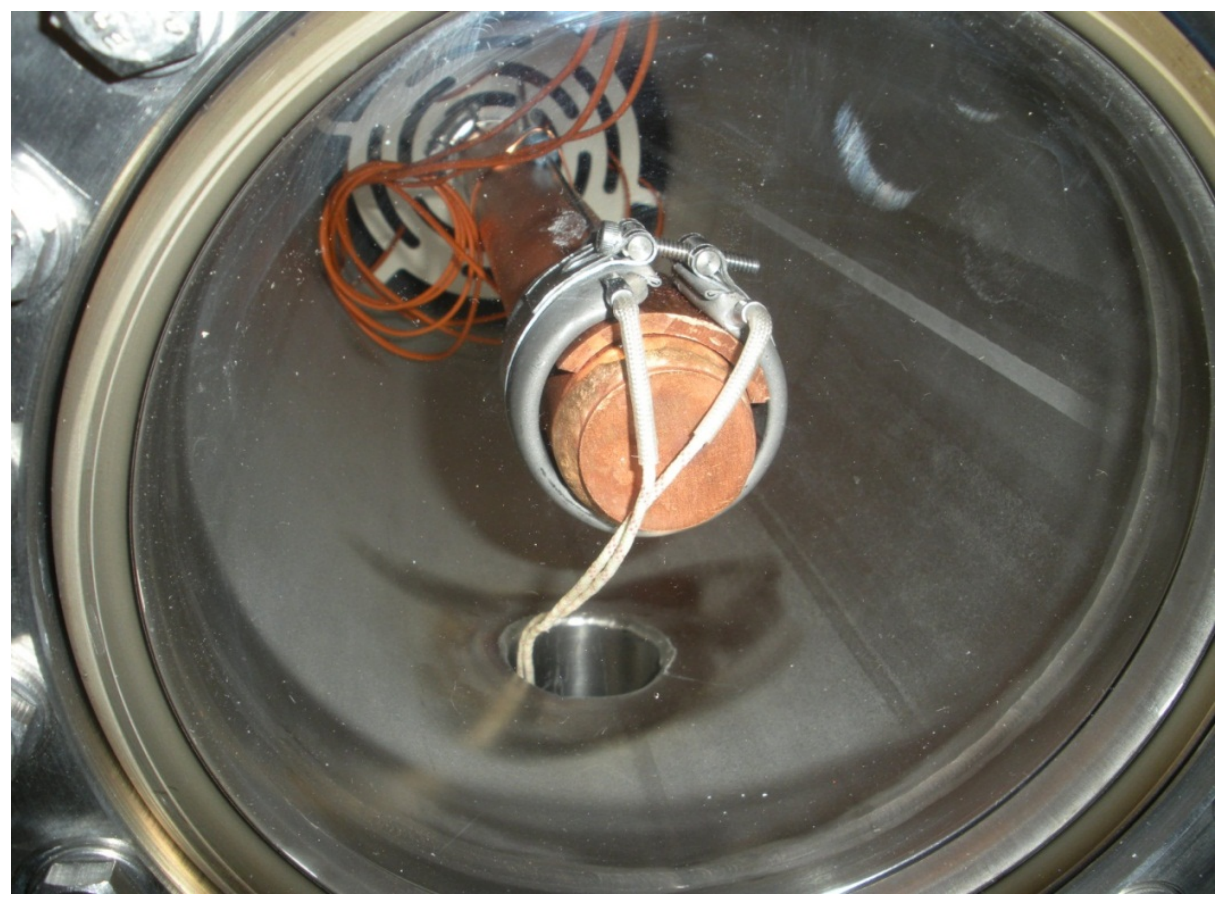

Figure 1.21. Band Heater Clamped at the End of the Copper Evaporator Tube 
Figure 1.22 shows the band heater power feedthrough.

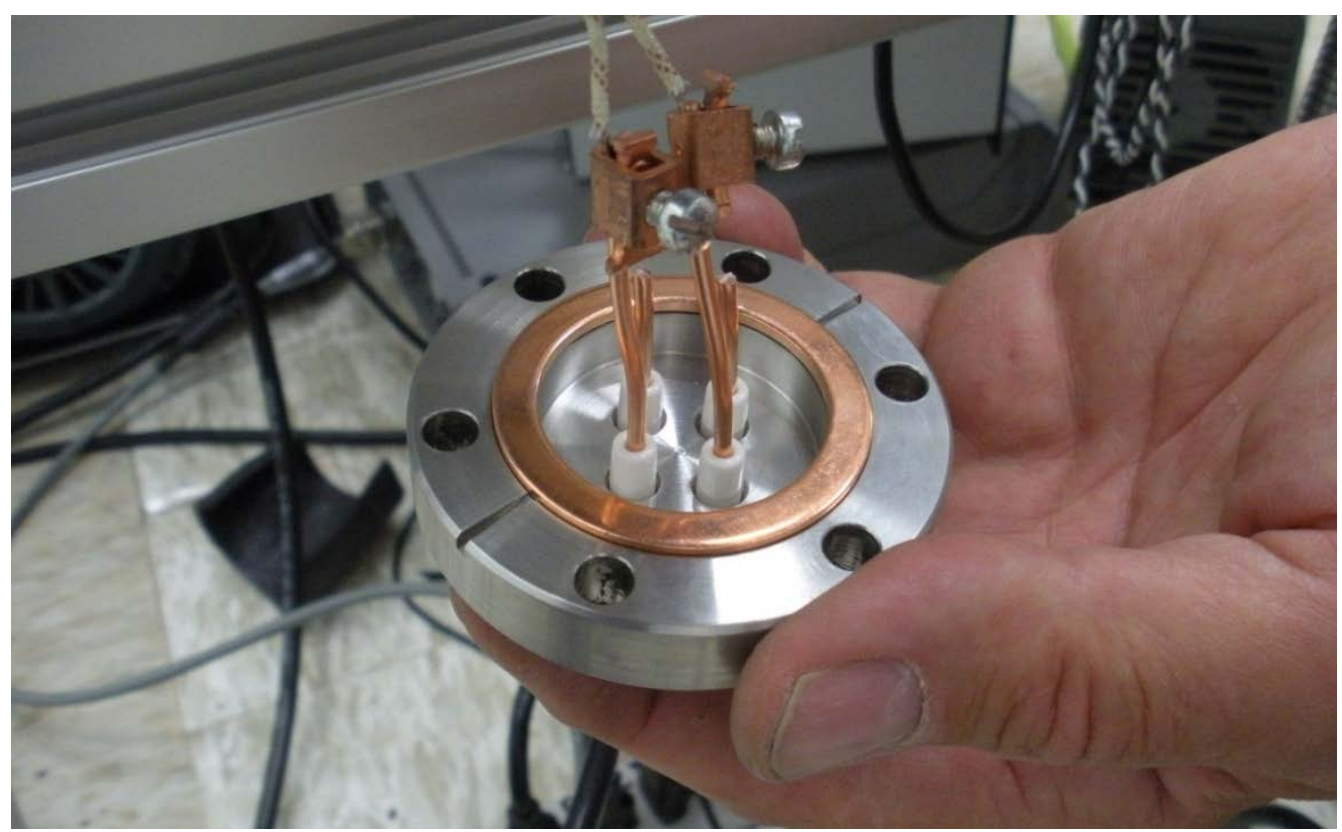

Figure 1.22. Heater Power Feedthrough

Figure 1.23 shows the thermocouple feedthrough.

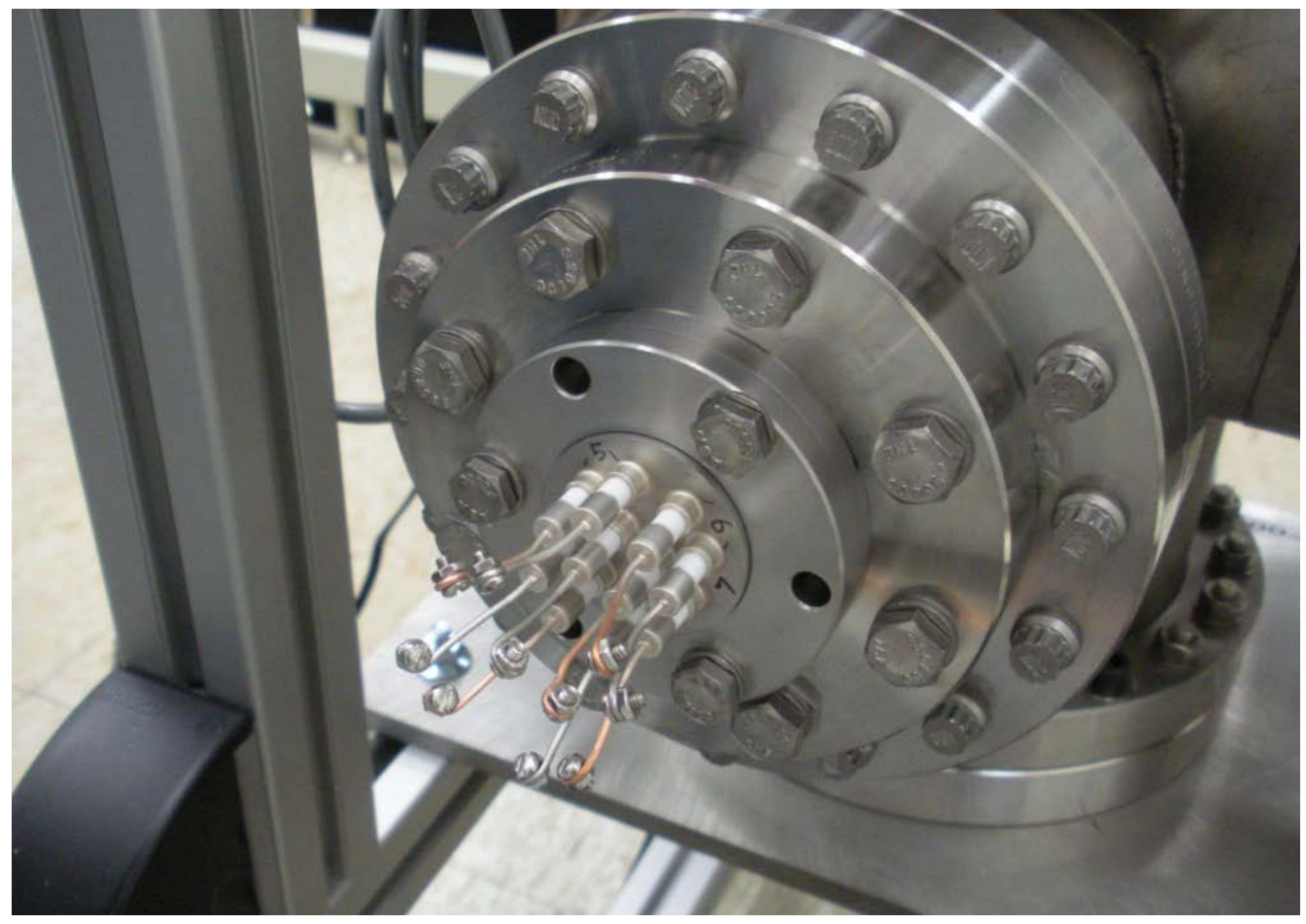

Figure 1.23. Thermocouple Feedthrough 


\subsection{Experimental Procedure and Results}

The experimentation with the thermosyphon system started using 15 psig nitrogen pressure at room temperature. The amount of initial nitrogen charge was increased to 50 psig at standard temperature and pressure for the majority of the measurements presented. The operating pressure was kept in the range of 0 to 4 psig to represent the anticipated operating conditions when the cold head is replaced with an open liquid nitrogen reservoir to cool the condenser. The two-phase equilibrium was reached at different heat loads and the temperature and pressure were held stable during all experimental runs. The temperature gradient across the evaporator tube has been evaluated and characterized across the operating range of the thermosyphon; experimental results can be found in Fast et al. (2010). 



\subsection{Conclusions}

With only minor design modifications, the thermosyphon experiment succeeded as a proof-ofprinciple experiment. The experiment showed excellent operation of the thermosyphon up to an applied $25 \mathrm{~W}$ heat load at the tip of the evaporator plus the thermosyphon base heat load of $9.4 \mathrm{~W}$, even without a downward tilt of the evaporator tube toward the tip. Testing to higher heat loads to evaluate suitability for applications such as a ton-scale system will require a new condenser cooling system that eliminates the thermal interface between the thermosyphon condenser and the cold sink. The proposed design for the MAJORANA DEMONSTRATOR will address this critical design issue. 

PNNL-20668

\subsection{References}

Fast JE, DJ Reid, and E Aguayo Navarrete. 2010. Majorana Thermosyphon Prototype Experimental Results. PNNL-20065, Pacific Northwest National Laboratory, Richland, Washington. 



\section{Distribution}

No. of

Copies

3 Pacific Northwest National Laboratory

DJ Reid

PDF

AD Guzman

PDF

JT Munley

PDF

Distr.1 


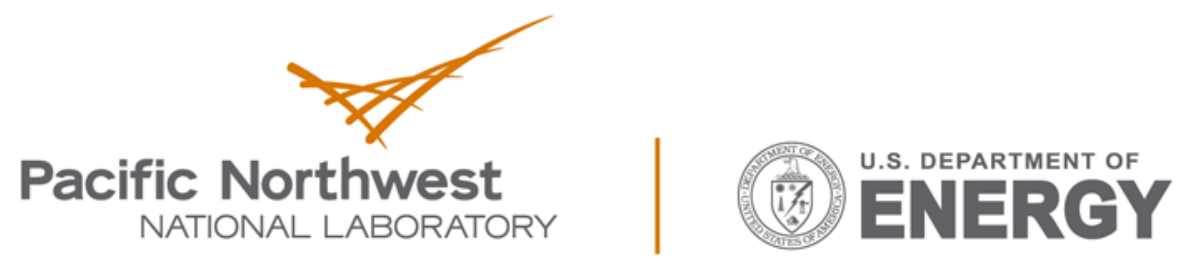

Proudly Operated by Battelle Since 1965

902 Battelle Boulevard

P.O. Box 999

Richland, WA 99352

1-888-375-PNNL (7665)

www.pnnl.gov 